\title{
ENTRE DidJaZÁ Y LA ZaNDUNGa: ICONOGRAFÍA Y AUTORREPRESENTACIÓN INDÍGENA DE LAS MUJERES Del istmo de Tehuantepec, OAXaca
}

\author{
Gabriela Zamorano Villarreal
}

$\mathrm{D}$ esde mediados de la década de 1980 el desarrollo de las tecnologías visuales ha permitido un mayor acceso a medios como la fotografía, el cine, y principalmente el video, facilitando sus usos alternativos, populares y comunitarios. Entre estos varios usos, el denominado video indígena ha tenido un fuerte impacto en todo el hemisferio americano. A la par del desarrollo de los medios indígenas han surgido numerosos debates en áreas tales como la antropología visual, los estudios culturales, la comunicación y, por supuesto, entre los mismos realizadores y promotores. Los aspectos que se han discutido en torno a los medios indígenas incluyen la forma en que el desarrollo tecnológico contribuye a la apropiación de los medios (Ginsburg, 1991); la diferencia entre la supuesta 'mirada indígena' y la mirada etnográfica o antropológica (Anaya, 1990; Ginsburg, 1991); y la importancia política y cultural de los medios indígenas (Ginsburg, Abu-Lughod y Larkin, 2002; Turner, 2002; Wortham, 2004).

En el intento de definir qué son los medios indígenas, de entender las diferencias de estos medios respecto a otras formas de representación visual y de explicarlos como una respuesta política alternativa a los medios

* Gabriela Zamorano Villarreal, Departamento de Antropología, City University of New York. masivos e incluso a las representaciones etnográficas, muchos estudios sobre la autorrepresentación indígena tienden a explicarla como algo radicalmente opuesto a otras formas de representación visual. De esta manera, a menudo se marca una dicotomía entre los medios indígenas y los no indígenas, o incluso entre la 'mirada indígena' y la 'occidental'.

Sin embargo, el término "video indígena" ha sido cuestionado desde diferentes frentes. Mientras algunos realizadores opinan que el video indígena es un proyecto diseñado por los antropólogos, otros preferirían enfatizar el aspecto comunitario o alternativo, y no el étnico, de los videos realizados en comunidades y organizaciones indígenas (Pérez Rojas, 2005). Por otra parte, realizadores y promotores han cuestionado si la categoría de "video indígena" es capaz de albergar las muchas tendencias y los diferentes géneros que exploran los y las realizadoras indígenas. Algunas de las preguntas en torno a esta categoría son: ¿Qué es entonces lo que hace indígena a un video? ¿La etnicidad del realizador? ¿Su formación y capacitación en relación con proyectos de video indígena? ¿El lugar donde se produce? ¿El hecho de que el video se haga en una comunidad indígena, o con participación indígena? ¿Qué sucede cuando un indígena realiza un video que no hace referencia a temas indígenas? 
Aunque resulta importante reconocer la existencia de proyectos visuales, principalmente de video, en el contexto de comunidades, organizaciones y luchas indígenas contemporáneas; resulta también necesario diluir los márgenes de lo que hasta ahora se ha explicado como medios indígenas y explorar más a fondo su relación histórica y política con otras formas de representación visual. Analizar esta relación, a menudo ambigua y contradictoria, puede ser útil para entender la producción de video e imágenes dentro de comunidades y organizaciones indígenas no como un proyecto esencialmente étnico, sino como un complejo proceso político en el que los imaginarios nacionalistas, regionales, raciales y de género se recrean, reproducen y transforman.

Cuestionando la existencia de lo que muchas veces se ha explicado como "la mirada india", el presente artículo pregunta cómo las imágenes producidas por indígenas existen en diálogo con otras representaciones visuales y escritas sobre lo indígena. Para ello retomaré algunas de las reflexiones que se han comentado alrededor de la abundante iconografía sobre las mujeres indígenas del istmo de Tehuantepec, y trataré de situarlas en relación con las autorrepresentaciones indígenas actuales.

La discusión se enfoca en tres aspectos. Primero, examino la manera en que el video indígena contribuye o cuestiona lo que Lerner denomina como el "vocabulario visual mexicanista". En segundo lugar, sugiero que estas representaciones al mismo tiempo participan en y resisten a la normalización de lo indígena. Finalmente, analizo la forma en que dichas representaciones se sitúan en relación con discursos multiculturalistas oficiales, en ocasiones incluso reforzándolas de forma no intencional. Estos aspectos pueden ser útiles para analizar las imágenes creadas por indígenas no simplemente como un importante instrumento de resistencia, sino también como una compleja práctica política inmersa en contradicciones y ambigüedades.

Las preguntas que abordo en este artículo son parte tanto de conversaciones y trabajo cercano a la capacitación, producción y circulación de videos con algunos realizadores y con organizaciones de medios en el estado de Oaxaca durante los últimos siete años, y de mi colaboración por tres años como asistente de programas latinoamericanos en el Centro de Cine y Video del Museo Nacional del Indio Americano, Instituto Smithsonian, en la ciudad de Nueva York; así como de ciertos debates teóricos sobre medios indígenas a partir de mi formación como antropóloga. Me interesa en particular reflexionar acerca de algunas de las tensiones y contradicciones que he observado a través de mi relación con estas experiencias. Mi enfoque en las mujeres del istmo se basa en dos años de colaboración en capacitación y producción de videos con quienes entonces conformaban la Comisión de la Mujer perteneciente a la Unión de Comunidades Indígenas de la Zona Norte del Istmo, UCIZONI — hoy Centro de los Derechos de la Mujer Nääxwiin, organización dedicada a la promoción de los derechos de las mujeres indígenas en los ámbitos de producción, salud, educación, comunicación, medio ambiente, y lucha contra la violencia.

\section{Entre Didjazá y la Zandunga: imaginando el istmo de Tehuantepec}

\footnotetext{
No he encontrado su nombre en mis notas, ya sea que lo he olvidado o que nunca lo haya oído, pero me acuerdo que algunos, por broma, delante de mí la llamaban la Didjazá, es decir, la zapoteca, en esta lengua. Recuerdo que la primera vez que la vi me quedé impresionado por su aire soberbio y orgulloso, por su riquísimo traje indígena, tan parecido a aquel con que los pintores representan a Isis, que creí ver a esta diosa egipcia o a Cleopatra en persona (Charles Brasseur en Viaje al Istmo de Tebuantepec, 1861 ${ }^{1}$
} 
Vemos fiestas pintorescas donde sobreviven costumbres ancestrales como la de marcar con rojo la cara, recordando la práctica española de marcar a indios y ganado. Vemos danzas, vestidos de diseños antiguos, oro, plata y encajes. Presenciamos la historia de amor de una mujer joven. A través de atuendos y ritos, su historia se mueve del amor a la boda. Y de su boda y el baile de la Zandunga hacia su afortunado hogar de sombras bajo las palmas (Sergei Eisenstein. The Making and Unmaking of Que Viva México). ${ }^{2}$

Didjazá y la Zandunga son dos figuras importantes en la imaginería acerca de las mujeres del istmo. Por un lado, la Didjazá descrita por el viajero francés Charles Brasseur a mediados del siglo XIX se presenta como una figura mítica de profundo erotismo y misterio, ad hoc con las fantasías orientalistas de los viajeros europeos. Por otra parte, la imagen de la Zandunga se retoma de un vals istmeño compuesto por Máximo Ramón Ortiz dedicado a las jóvenes que bailaban en las celebraciones o "velas" zapotecas, y aparece como una graciosa figura femenina en incontables imágenes, personajes de cine y demás representaciones referentes a esta región (Zarauz, 2004). En esta sección describo la manera en que este tipo de figuras han sido retomadas como emblemas nacionales, de la región y de la oaxaqueneidad.

Preguntas sobre las representaciones del istmo de Tehuantepec son particularmente relevantes si las situamos en la actualidad de la región, principalmente en relación con el Plan Puebla Panamá, proyectado originalmente en la zona del istmo de Tehuantepec. Este plan es una de las más controvertidas iniciativas de desarrollo económico en el sur de México y Centroamérica. El proyecto, promovido por el presidente Vicente Fox como un plan de desarrollo dedicado a reducir los contrastes entre el norte y el sur del país ${ }^{3}$ reúne muchas de las posibilidades que inspiraron a los viajeros extranjeros durante el siglo XIX. El Plan Puebla Panamá también trae de vuelta debates de cómo "integrar" a la población local en los planes nacionales e internacionales, y está actualmente enfrentando nuevas formas de resistencia indígena.

Históricamente, la región del istmo de Tehuantepec ha sido objeto de innumerables narraciones y representaciones por parte de viajeros, escritores, misioneros, inversionistas, antropólogos, fotógrafos, cineastas y pintores. El interés histórico por la región se relaciona con sus características geográficas, demográficas y políticas. Por un lado, el istmo ha sido visto de manera permanente como una zona ideal para el comercio y la comunicación internacional debido a que vincula los océanos Pacífico y Atlántico. Por otra parte, la región ha sido descrita como extremadamente exótica debido a la biodiversidad ecológica y a la variedad de pueblos indígenas que se concentran allí. Entre los muchos aspectos que llaman la atención de viajeros, artistas y estudiosos, las mujeres del istmo ocupan un lugar central.

Casi cualquier representación del istmo dedica un esfuerzo especial para describir a sus mujeres. Las istmeñas - particularmente tehuanas y juchitecas — han sido descritas como fuertes, valientes, misteriosas, independientes, temerarias, libres y elegantes. En muchas ocasiones se les muestra además fuertemente sexualizadas: particularmente hermosas, sensuales, delicadas y graciosas (Brasseur, 1861; Covarrubias, 2000; Eisenstein, 2000; Iturbide y Poniatowska, 1989; Starr, 1908). Además, como detalla Zarauz (2004), desde inicios del siglo XIX imágenes de mujeres istmeñas salpican o saturan la pantalla cinematográfica a través de películas que van desde las clásicas Que Viva México de Sergei Eisenstein (1932), La Zandunga de Fernando de Fuentes (1937) y Rincón Brujo de Alberto Gout (1949), hasta trabajos más experimentales como Totopo Güero de Claudio Zangarini (1991). Zarauz analiza cómo estas innumerables imágenes de mujeres istmeñas en el cine las representan con ciertos perfiles morales que van "de la voluptuosidad al recato", informadas por narraciones de viajeros y por estereotipos nacionalistas de la femineidad mexicana (Imagen 1). 


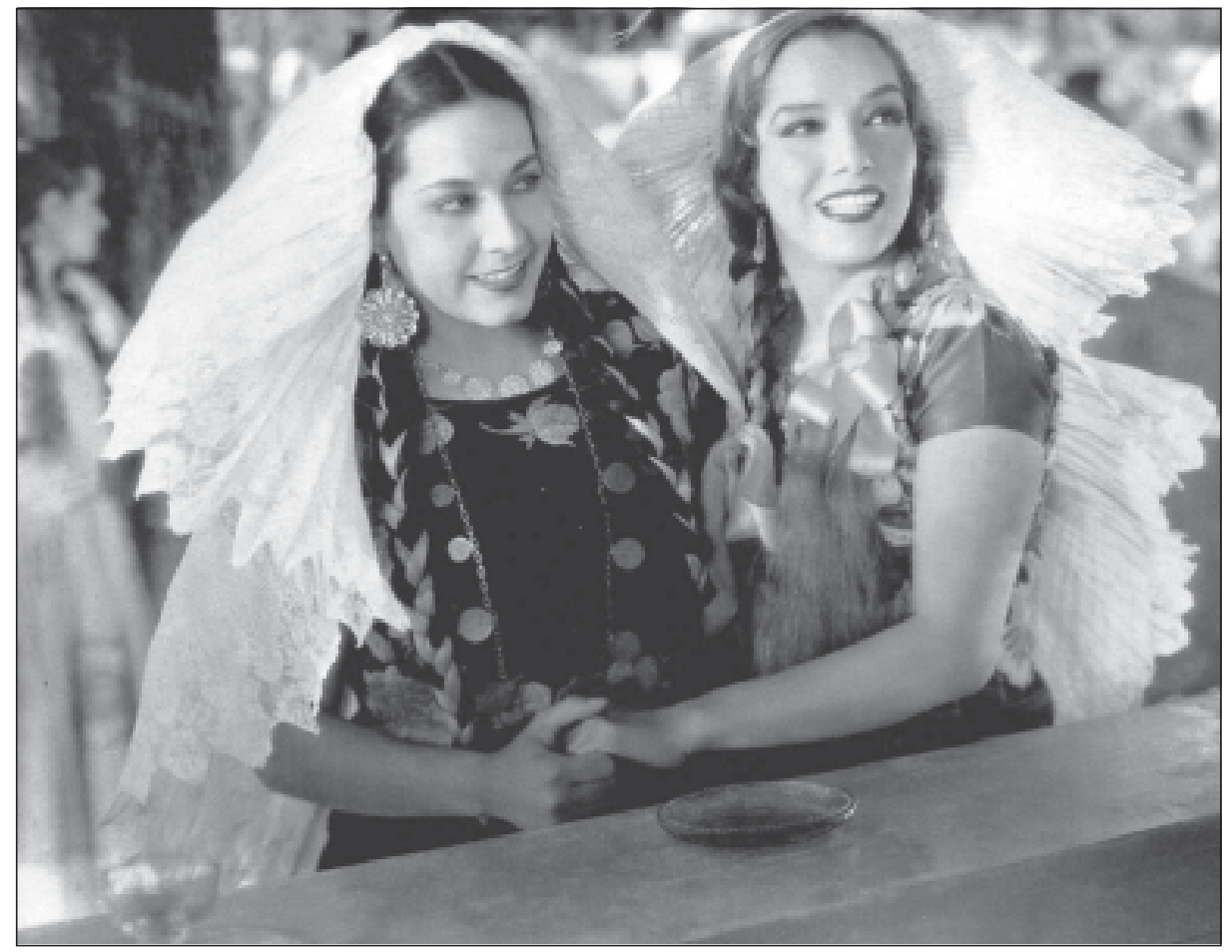

1. Maria Luisa Zea y Lupe Vélez. Fotograma de la película La Zandunga, dirigida por Fernando de Fuentes. 1937. (Tomado de "La Tehuana” Artes de México No. 49, 2000, p.23).

Así, incontables relatos e imágenes abundan en detalles sobre las formas corporales, movimientos, gestos y tono de piel de las istmeñas; enfatizando la importancia de su vestido como parte esencial de su belleza. Estas imágenes han contribuido a la idea de que el istmo es de los pocos lugares donde se ejerce, de manera tradicional y natural, el matriarcado, o donde, por ejemplo, los muxes u homosexuales no sólo son tolerados sino que forman parte intrínseca de la estructura tradicional familiar (Miano Borruso, 2001). A continuación discuto cómo esta visión de las mujeres istmeñas ha sido movilizada históricamente en el imaginario nacionalista, cuestionando al final de la sección de qué forma las autorrepresentaciones indígenas participan o confrontan este imaginario.

\section{Autorrepresentaciones indígenas y el "vocabulario visual mexicanista"}

En su estudio sobre las fotografías de Hugo Brehme, Jesse Lemer habla de la importancia de la difusión masiva de fotografías en la época posrevolucionaria para crear una especie de 'vocabulario visual mexicanista' (2002: 30). El imaginario de lo mexicano — explica Lernerse crea en una compleja combinación de esfuerzos de instituciones, talentos, mercados y necesidades político ideológicas tanto dentro como fuera del país. En lo específico de imágenes de mujeres indígenas en el istmo, podemos hablar también de vocabularios visuales indigenistas y regionales a partir de los cuales se define 
"lo istmeño" y la "oaxaqueneidad". Numerosos retratos de cuerpo entero o de medio cuerpo, generalmente policromados, muestran hermosas y sonrientes mujeres ataviadas con el vestido típico istmeño: huipil y nagua bordados con vistosas flores; pesados aretes, collares, anillos y pulseras de oro; y el resplandor, un amplio tocado blanco alrededor de la cabeza.

En este vocabulario visual, la imagen de la tehuana —que incluso llegó a estar impresa en billetes mexicanos - se construye como parte de la iconografía mexicanista compuesta por pintorescos paisajes de sembradíos, tlachiqueros, iglesias y tantos otros símbolos neutrales a través de los cuales se moviliza el orgullo indígena en el imaginario mexicano (Lerner, 2002: 8; Pérez Monfort, 2000). Desde la época posrevolucionaria, este tipo de imágenes circularon en ferias mundiales, exhibiciones industriales, revistas ilustradas y demás medios impresos nacionales e internacionales (Trillo Tenorio, 1999). Como Poole (2001) indica, en esta iconografía la imagen de la tehuana utiliza el vestido y el cuerpo femenino para facilitar la asociación de raza y región en la imaginación popular (Imagen 2).

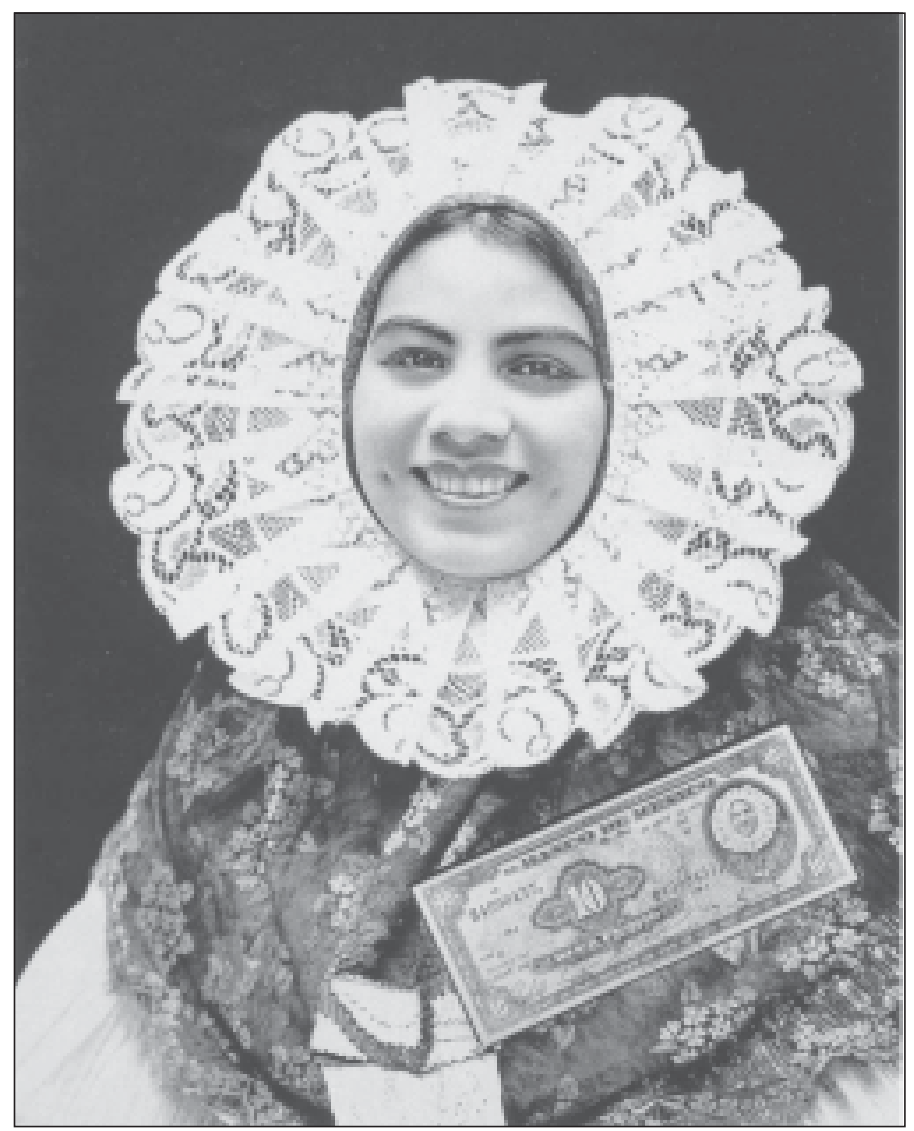

2. Imagen de Tehuana utilizada para los billetes de 10 pesos en 1959. Rafael García., Estela Ruiz, 1937. (Tomado de "La Tehuana" Artes de México No. 49, 2000, p.20). 
Dichas imágenes forman parte importante del ambiguo imaginario mexicano sobre lo indígena que ha sido impulsado desde la época posrevolucionaria. En el discurso nacionalista dado después de la Revolución es necesario exaltar un origen y pasado glorioso de culturas prehispánicas y una imagen limpia y colorida de lo indio, al tiempo que es importante negar la marginación en la que han vivido y en la que viven los pueblos indígenas. Esta ambigüedad se refleja también en las bases del indigenismo, donde intelectuales como Manuel Gamio, José Vasconcelos, y Frederick Starr proyectaban 'rescatar' o exaltar las cualidades de las "razas" y culturas indígenas que podían contribuir al proyecto civilizatorio nacional. Por un lado, se promovía la idea de que los indígenas son emprendedores, honestos, trabajadores y nobles; por el otro, se proyectaba erradicar sus características "negativas" - tales como la supuesta ignorancia, necedad, o arraigo a costumbres retrógradas- $\mathrm{Al}$ respecto Starr dice:

De los aztecas, tlaxcaltecas, mixtecos, zapotecos y mayas, podemos esperar mucho en el futuro. Fueron razas de logros en el pasado, y los monumentos de sus logros aún permanecen [...]. Que los otomíes, triquis o mixes puedan ser transformados por las escuelas es dudoso [...] Personalmente siento que la prosperidad de México descansa más en la sangre india que en cualquier otro elemento de poder nacional. Que las escuelas harán mucho para capacitar a las tribus más dotadas quizá es verdad. Pero hay de indios, a indios, en México (1908: 938). ${ }^{4}$

Desde fotografías de tipos indígenas como el proyecto de Frederick Starr a principios del siglo xx (Starr, 1908), hasta proyectos etnográficos indigenistas (Gamio, 1992); desde la seductora Didjazá descrita por Brasseur a su paso por Tehuantepec hasta la graciosa Zandunga interpretada por Lupe Vélez en la película de
Fernando de Fuentes (1938); desde el muralismo de los años treinta hasta las imágenes de realismo mágico de Graciela Iturbide y Mariana Yampolski; desde el México de Eisenstein y Covarrubias hasta los vestidos de Kahlo, desde las funcionarias oaxaqueñas hasta la representante de Oaxaca en el certamen de belleza Señorita México, la imagen de la tehuana forma parte de lo que Roger Bartra explica como la hegemonía del simbolismo visual. La istmeña colorida, sensual, fértil, líder, libre, risueña, candente, florida y apegada a la tierra se celebra como una imagen de orgullo indígena nacional —ese orgullo a la vez compasivo y nostálgico que tiene la mirada occidental hacia "el otro".

$\mathrm{Al}$ analizar autorrepresentaciones indígenas vale preguntarse cómo se insertan en estas retóricas nacionalistas, indigenistas o regionalistas. Mi idea es que no necesariamente constituyen una mirada independiente, ajena, coherente y opuesta a esta infinita riqueza de representaciones, sino que más bien participan con ellas de manera contingente, como en un diálogo, en ocasiones reproduciéndolas, y al mismo tiempo transformándolas. Para entender algunos aspectos de este complejo diálogo, sugiero que futuros estudios sobre el "video indígena" podrían analizar las limitaciones y posibilidades del contexto económico y político en el que se producen, circulan y legitimizan las autorrepresentaciones visuales de lo indígena. Esto incluye mirar aspectos como financiamiento, reconocimiento local e internacional, así también las demandas y tensiones de representación dentro y fuera de las comunidades y organizaciones.

Uno de los aspectos que nos permitiría ubicar cómo las autorrepresentaciones visuales indígenas participan en la iconografía nacionalista sería analizar los procesos de circulación, consumo y reconocimiento de dichas imágenes en diferentes contextos. En la siguiente sección exploro algunas de las implicaciones de la circulación de representaciones visuales. 


\section{Normalizando lo indígena}

El artículo de Leigh Binford sobre las fotografías de Graciela Iturbide critica arduamente la iconografía de las istmeñas, las cuales fueron editadas con un festivo prefacio de Elena Poniatowska en el libro Juchitán de las Mujeres. ${ }^{5}$ En este estudio, Binford dice que el trabajo de Iturbide reafirma los discursos liberales que glorifican la fuerza, dignidad y poder de los indígenas. $\mathrm{Al}$ presentar esta imagen pintoresca y celebratoria, Iturbide, como muchos otros viajeros, artistas, académicos e intelectuales, construye una visión de lo nativo aceptable en el occidente. Sin embargo, Binford continúa... al exaltar el supuesto matriarcado, la supuesta aceptación tradicional de la homosexualidad, y la supuesta libertad y autonomía de las mujeres istmeñas, se dejan fuera los conflictos que circunscriben esta imagen, todo aquello que se encuentra, por decirlo así, "fuera de cuadro".

Mujeres de organizaciones políticas del istmo, ${ }^{6}$ al igual que algunos antropólogos con mirada escéptica a las ideas de matriarcado en la zona como Binford (1996), Fusco (1991) y Rubin (1997), afirman que la imagen celebratoria de las mujeres istmeñas oscurece el entendimiento de los conflictos de poder dentro de la casa, comunidades y organizaciones políticas. Esta imagen no considera, por ejemplo, la intensa violencia intrafamiliar, las costumbres respecto a la virginidad, ni incluso la manera en que líderes de organizaciones movilizan estas mismas imágenes celebratorias para legitimizar y financiar el trabajo de la organización. Videos y otras formas de representación visual que abordan parcialmente estas problemáticas constituyen un punto de tensión ante imágenes glorificantes de lo indígena, o del supuesto poder casi innato de las mujeres istmeñas. Por ejemplo, en la película Tejiendo Mar y Viento. La Vida de una Familia Ikood (Luis Lupone y Teófila Palafox, 1987), Teófila Palafox, primera mujer indígena mexicana en recibir una prestigiosa beca para producir medios audiovisuales, menciona que le gusta el video porque le permite acceder a mundos a los que no tiene acceso normalmente como mujer en su pueblo San Mateo del Mar, comunidad ikood o huave localizada en el istmo de Tehuantepec. El testimonio de Palafox se escucha mientras miramos su imagen en una lancha en medio del mar, documentando una jornada de pesca en la que normalmente sólo los hombres participan.

Palafox es de las pocas mujeres indígenas que han realizado video en México. Es interesante que una de las imágenes más circuladas en los inicios de la promoción del video indígena sea justamente la fotografía de Palafox y otra mujer ikood filmando en su comunidad con unas pequeñas cámaras de cine (Imagen 3). 


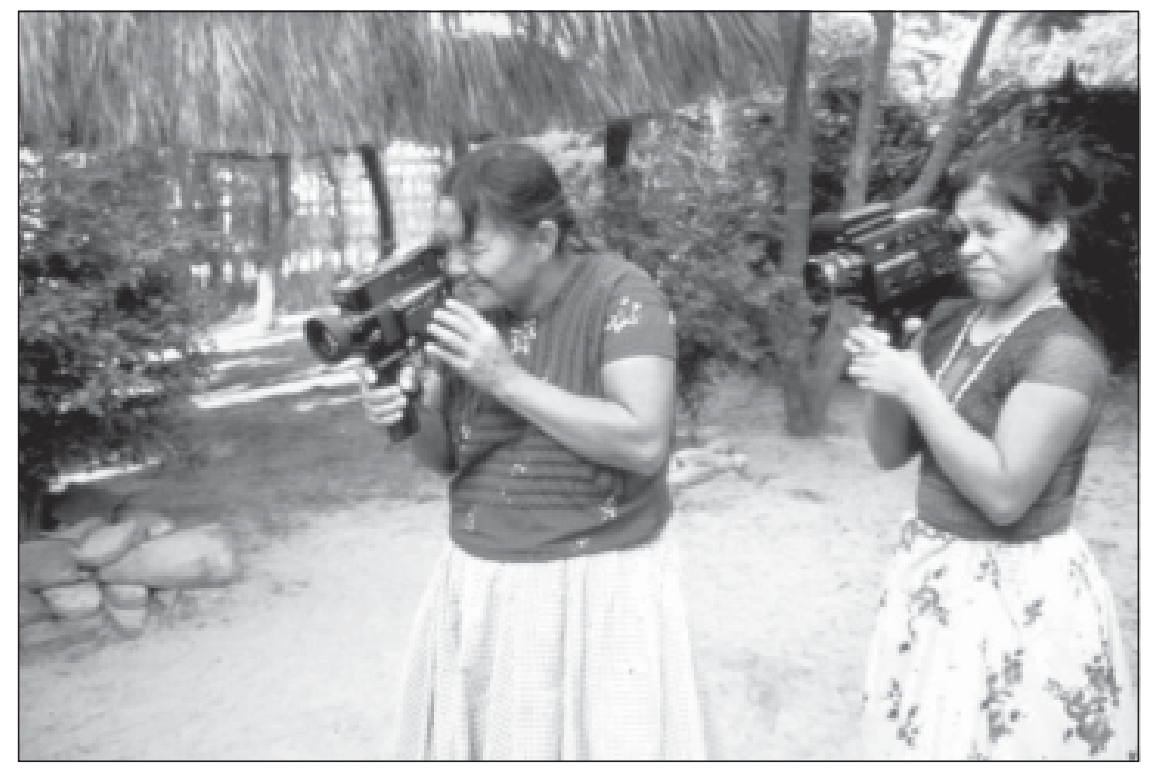

3. Imagen de Tejiendo Mar y Viento. La Vida de una Familia Ikood. San Mateo del Mar, Oaxaca, 1985. Cortesía de la Comisión Nacional para el Desarrollo de los Pueblos Indígenas de México. Foto: Alberto Becerril.

El uso de esta imagen tiene mensajes ambiguos. Por una parte, al mostrar a dos mujeres indígenas utilizando las cámaras, esta fotografía sintetiza la idea de empoderamiento a través de la apropiación del video, la cual fue uno de los objetivos centrales del proyecto Transferencia de Medios. ${ }^{7}$ La idea de empoderamiento se acentúa por el hecho de que son dos mujeres quienes utilizan las cámaras. Aunque esta imagen funciona para demostrar que es posible que indígenas — principalmente mujeres - utilicen el video para sus propios fines; en ciertos contextos de circulación el uso excesivo de este tipo de fotografías sirve también para atraer la atención o cumplir con las expectativas de equidad de género de ciertos públicos y agencias financiadoras. Así, el abundante uso de imágenes de mujeres indígenas con cámaras de video en folletos promocionales, carteles y catálogos de festivales, contrasta con el hecho de que muy pocas realizadoras indígenas logran mantenerse activas en la producción de video, debido en parte a dificultades de financiamiento pero sobre todo a problemas familiares, comunitarios u organizacionales que surgen a partir de su trabajo como videastas.

Otro ejemplo de este tipo de tensiones fue la presentación de Abriendo Brecha en la Asamblea Congreso de la UCIZONI, video que realizamos - mujeres indígenas y no indígenas - dentro de la Comisión de la Mujer en 1999. ${ }^{8}$ Abriendo Brecha documenta diez años de experiencia organizativa de las mujeres de la región. Durante los comentarios y preguntas al final de la muestra un delegado se puso en pie, diciendo que le gustó mucho el video pero que le sorprendió que muy pocos hombres dieran sus testimonios. Las mujeres le explicaron que el video intentaba hacer visible una experiencia que no tenía mucha presencia en la organización, y que por ello enfatizaba la presencia femenina. 
Los ejemplos anteriores muestran algunas de las tensiones que circunscriben las autorrepresentaciones indígenas, tales como la pregunta de quién y a quiénes se representa cuando hablamos de autorrepresentación. En relación con el proyecto de video indígena, uno de los retos más complejos de éste es la posibilidad de hacer visibles ciertos aspectos, demandas o experiencias de grupos - en este caso de los pueblos indígenasque debido a relaciones históricas desiguales han sido marginados del proyecto nacional. El video indígena se ha presentado como una herramienta a través de la cual los pueblos indígenas pueden contar sus propias historias y de esta forma demandar, desde sus propias miradas, cierto reconocimiento político (Anaya; Ginsburg, Abu-Lughod y Larkin; Turner; Wortham: op. cit.). Esta premisa confronta el reto de la heterogeneidad de voces y miradas, así como de las relaciones de poder dentro de las mismas comunidades y organizaciones indígenas a las que se intenta representar. Por otra parte, la premisa confronta también el reto de cómo lograr el reconocimiento político a las demandas actuales de los pueblos indígenas en un contexto global de neoliberalismo económico y político. A través de una discusión sobre autorrepresentación, multiculturalidad y política neoliberal, en la siguiente sección expongo algunas preguntas que serían útiles para pensar en la función de las representaciones visuales en contextos específicos de poder político.

\section{Autorrepresentación y multiculturalidad}

En dos escritos recientes, Deborah Poole analiza cómo lo visual contribuye a reforzar o legitimar discursos estatales (2001 y 2004). Esta pregunta es particularmente interesante en el contexto del estado neoliberal, donde el discurso oficial se maneja como tolerante y promotor de la diversidad cultural. En este sentido, el reconocimiento estatal de la multiculturalidad se utiliza más como una forma de legitimar la gobernatura neoliberal que para implementar políticas reales en contra de la marginación histórica de los pueblos indígenas. $\mathrm{Al}$ respecto Charles Hale explica:

$[\mathrm{P}]$ oderosos actores políticos y económicos utilizan el multiculturalismo neoliberal para afirmar la diferencia cultural, al mismo tiempo que mantienen la prerrogativa de discernir entre derechos culturales congruentes con el ideal liberal, el pluralismo democrático, y los derechos culturales intrínsecos a ese ideal. Al hacer esto, avanzan una ética universalista que constituye la defensa del orden capitalista neoliberal (2002: 491).

En el ámbito del multiculturalismo oficial, el vestido y la figura de la mujer istmeña también se encuentran presentes. Poole nota cómo el gobierno de Diódoro Carrasco, principal promotor oficial de lo multicultural como esencia de lo oaxaqueño, está documentado por fotografías de prensa de funcionarias y acompañantes de Carrasco en visitas internacionales, vestidas con coloridos huipiles istmeños. Más adelante, Poole analiza en detalle la celebración de la Guelaguetza oaxaqueña como un evento que embiste muchas de las contradicciones de la imaginería sobre lo indígena. En la Guelaguetza los diferentes pueblos muestran al mundo con orgullo parte de sus vestidos, costumbres y tradiciones. En la Guelaguetza también los políticos, recibiendo regalos de los danzantes frente a una cámara de prensa, afirman la "retórica celebración de la diversidad por sí misma como base de una cultura oaxaqueña unificada" (Poole, 2001: 10). Uno de los aspectos más interesantes de la Guelaguetza es el "Comité de Autenticidad", especie de jurado étnico que viaja a cada una de las siete regiones para "cuidar que las delegaciones realmente se presenten con la autenticidad y dignidad de su grupo étnico" (citado por Poole, ibid., p. 12). Los procedimientos, criterios y argumentos que certifican la autenticidad son complejos 
y no parte del presente análisis. Sin embargo, el ejemplo y las preguntas que Poole plantea al respecto pueden ser útiles para pensar también el tema de la autorrepresentación audiovisual. Acerca del comité de autenticidad, Poole pregunta cómo "la sombra del Estado invade y autoriza los 'sentimientos' o criterios evaluadores de la autenticidad étnica”. Esta pregunta propone una visión del Estado no como institución monolítica que se impone sobre lo indígena, sino una entidad que funciona y se reproduce a través de prácticas políticas y culturales tanto por parte de los gobernadores y funcionarios estatales, como por parte de los pueblos indígenas (Poole, 2001: 5). De esta manera, la celebración de la Guelaguetza — práctica que originalmente simbolizaba el intercambio económico entre los diferentes pueblos indígenasperpetúa tanto el poder estatal que ahora se legitima a través de discursos multiculturales; como la idea entre ciertos sectores de los pueblos indígenas de ser reconocidos y de mantener cierto prestigio y visibilidad a través de sus manifestaciones culturales.

Las preguntas de Poole son inspiradoras para pensar acerca de la producción de video indígena. Guardando las comparaciones, podríamos argumentar que tanto la Guelaguetza como el denominado video indígena son prácticas culturales llevadas a cabo "desde adentro", por indígenas. Como los ejemplos de Poole sugieren, el hecho de que una práctica cultural esté diseñada y legitimada por indígenas no necesariamente significa que se encuentre fuera de "la sombra del Estado". En ocasiones incluso ésta puede servir para legitimarlo, particularmente en contextos donde los discursos multiculturales oficiales se sostienen a partir de todo tipo de ambigüedades. Claramente, el denominado video indígena se hace y circula a una escala mucho menor que la Guelaguetza, y se da de manera más heterogénea y diversa de acuerdo con los géneros, objetivos y contextos en los que se produce. Sin embargo, su producción y circulación bajo la categoría de video indígena está informada por el discurso multicultural oficial, y podría, en ciertos contextos de circulación y quizá contra todo objetivo de los realizadores indígenas, incluso legitimar la política multiculturalista del Estado. No podemos olvidar por ejemplo que la propia iniciativa de la "Transferencia de Medios Audiovisuales a Comunidades Indígenas" surgió en el seno del que entonces era Instituto Nacional Indigenista a fines de la década de 1980 (Anaya, 1990), en un contexto en el que el Estado mexicano comenzó a reformular su política en torno a un discurso pluricultural (Wortham, 2004).

Con estas observaciones no pretendo de ninguna manera decir que el video indígena esté al servicio del Estado. Al enfatizar y valorar su función como una importante herramienta de resistencia y propuesta de sectores sociales que han sido históricamente marginados, es importante también notar que, como todas las otras formas de resistencia política, existe en una compleja dinámica de relaciones de poder tanto dentro de comunidades y organizaciones indígenas como en relación con el Estado y con las políticas e instituciones globales.

Con base en estos ejemplos, y tomando en cuenta la proximidad entre las autorrepresentaciones indígenas y los movimientos sociales, resulta importante reflexionar qué tanto, y desde dónde, las autorrepresentaciones visuales de lo indígena cuestionan o contribuyen a iconografías estereotípicas.

\section{Conclusiones}

Con las preguntas anteriores propongo notar la importancia de diluir los límites de lo que hasta ahora se ha manejado como video indígena, con el fin de entender este proyecto de representación alternativa no sólo como una exitosa experiencia de resistencia cultural y de autorrepresentación a favor de grupos marginados históricamente, sino como una práctica política inmersa en complejas relaciones de poder. 
Utilizando como guía una serie de preguntas que se han compartido sobre los usos políticos de imágenes de las mujeres del istmo, propongo pensar la producción de autorrepresentaciones visuales indígenas como parte de un diálogo donde, aunque representando lo propio, están informadas, permeadas y en conversación con otras imágenes de lo indígena. Primero, he discutido cómo la imagen de la tehuana formó parte de un "vocabulario visual mexicanista" a través del cual se utilizaron ciertos iconos con el fin de crear un imaginario nacionalista unificador a partir de la época posrevolucionaria. En segundo lugar he explorado cómo ciertas imágenes glorificantes sobre lo indígena, al ser circuladas en contextos internacionales, contribuyen a normalizar lo indígena conforme a ciertas expectativas liberales; preguntando cómo las imágenes creadas por los indígenas contribuyen o cuestionan este tipo de representaciones. Mientras algunos videos elaborados por indígenas intentan mostrar la unidad de las comunidades y la importancia de los valores tradicionales evitando mostrar las tensiones y contradicciones internas; otros videos también realizados por indígenas enfatizan puntos de tensión y conflicto al interior de comunidades y organizaciones. Esta tensión al momento de representar lo propio constituye uno de los retos más importantes de la autorrepresentación.

Finalmente, exploro cómo el vocabulario visual mexicanista analizado por Lerner en el contexto nacionalista posrevolucionario se reformula en el actual contexto de política neoliberal, donde la adopción del discurso multicultural se promueve como una de las principales cualidades de la nueva democracia estatal. $\mathrm{Al}$ respecto, propongo mirar en futuros estudios sobre video indígena los mecanismos a través de los cuales esta forma de representación participa o resiste a la nueva modalidad de poder del Estado.

A lo largo de este artículo argumento que no basta con que las representaciones visuales sean producidas por indígenas, o con participación indígena, para constituir una mirada alternativa, una "mirada india" o "desde adentro". Lo indígena mismo ha sido un concepto político, promovido y transformado históricamente en relación con un proyecto nacional, y en consecuencia dado a conocer por discursos estatales y ciertos "vocabularios visuales nacionales". En otro sentido, la diversidad de contextos de capacitación, producción, financiamiento y circulación de videos realizados por indígenas está siempre en diálogos contingentes con otras formas de representación, frecuentemente renegociando y transformando los estereotipos, aunque en ocasiones también reproduciéndolos. Mediante estas preguntas y observaciones, me interesa enfatizar la necesidad de mirar las autorrepresentaciones visuales como una serie de prácticas donde las complejidades de lo político pueden ser analizadas.

\section{Notas}

${ }^{1}$ Citado de: Brasseur, Charles, 2000, “La Didjazá”, en Artes de México, Núm. 49, pp. 12-13.

${ }^{2}$ Citado de: Eisenstein, Sergei, 2000, "La Vida", en Artes de México, Núm. 49, pp. 14-15.

${ }^{3}$ Citado del documento oficial del Plan Puebla Panamá: Plan Puebla Panamá, Introducción, página 1, en http:// ppp.presidencia.gob.mx/main.html. Junio 2001.

4 "From the Aztecs, the Tlaxcalans, Mixtecs, Zapotecs and Mayas, we might hope much in the future. They were races of achievement in the past, and the monuments of their achievement still remain [...] That the Otomis, the Triquis, or the Mixes, should be made over by the schools is doubtful [...] Personally I feel that the prosperity of Mexico rests more upon the Indian blood than on any other element of national power. That schools will do much to train the more gifted tribes perhaps is true. But there are Indians, and Indians, in Mexico" (1908: 938) [Mi traducción al español].

${ }^{5} \mathrm{Al}$ respecto Poniatowska dice: "Juchitán is not like any other town. It has the destiny of its Indian wisdom. Everything is different; women like to walk embracing each 
other, and here they come to the marches, overpowering with their iron calves. Man is a kitten between their legs, a puppy they have to admonish, 'stay there'. They walk touching each other playfully. They trade roles: they grab men and watch them before the fence, pulling at them, fondling them as they curse the government and sometimes, men themselves. They are the ones who participate in demonstrations and beat policemen" (Citada en Binford, 1996: 244).

${ }^{6}$ Particularmente de la Coalición Obrera Campesina Estudiantil del Istmo, COCEI, y de la UCIZONI.

${ }^{7}$ El proyecto Transferencia de Medios Audiovisuales a Comunidades Indígenas, diseñado por el Instituto Nacional Indigenista, fue uno de los principales promotores de producciones indígenas en México.

${ }^{8}$ Zamorano, Gabriela y Fabiola Gervacio. Abriendo Brecha. Comisión de la Mujer/ UCIZONI, 1999.

\section{Bibliografía}

Anaya, Graciela (ed.), 1990, "Hacia un video indio", INI Cuadernos 2, Archivo etnográfico audiovisual, Instituto Nacional Indigenista, México.

Bartra, Roger, 1996, "Stuffing the Indian Photographically", History of Photography 20(3), Estados Unidos, pp. 23639.

Bennholdt-Thomsen, Veronika, 1997, Juchitán, la Ciudad de las Mujeres, Instituto Oaxaqueño de las Culturas; Fondo Estatal para la Cultura y las Artes, Oaxaca, México.

Binford, Leigh, 1996, "Graciela Iturbide: Normalizing Juchitán”, History of Photography 20(3), Estados Unidos, pp. 244-248.

Brasseur de Bourbourg, Charles Etienne, 1861, Viaje por el Istmo de Tehuantepec, FCE, México.

Brígido-Corachán, Anna, 2004, “An interview with Juan José García, President of Ojo de Agua Comunicación", American Anthropologist, Vol. 106, Núm. 2, pp. 368-373.

Covarrubias, Miguel, 2000, "Mirando Hacia el Sur", Artes de México: La Tebuana, Núm. 49, México, pp. 26-37.

Eisenstein, Sergei M, 2000, "La Vida", Artes de México: La Tehuana, Núm. 49, México, p. 15.

Fusco, Coco, 1991, "Essential Differences: photographs of Mexican women”, Afterimage 18, Estados Unidos, pp. 11-13.

Gamio, Manuel, 1992, Forjando Patria, Editorial Porrúa, México.
Ginsburg, Faye, 1991, "Indigenous Media: Faustian Contract or Global Village?" Cultural Anthropology, Vol. 6, Núm. 1, pp. 92-112.

Ginsburg, Abu-Lughod y Larkin, 2002, “Introduction”, en F. Ginsburg, L. Abu-Lughod y B. Larkin (eds.) Media Worlds: Anthropology on New Terrain, University of California Press, Berkeley, pp. 1-36.

Hale, Charles, 2002, "Does Multiculturalism Menace? Governance, Cultural Rights and the Politics of Identity in Guatemala", Journal of Latin American Studies, Vol. 34, Núm. 3, pp. 485-524.

Iturbide, Graciela y Elena Poniatowska, 1989, Juchitán de las Mujeres, Ediciones Toledo, México.

Lerner, Jesse, 1996, "Images of the Subverted Eden", History of Photography 20(3), Estados Unidos, pp. 239-244.

—, 2002, "La Exportación de lo Mexicano. Hugo Brehme en Casa y en el Extranjero", Alquimia-Hugo Brehme. Los prototipos mexicanos 6(16), México, pp. 30-38.

Miano Borruso, Marinella. 2001, Género y Homosexualidad entre los Zapotecos del Istmo de Tehuantepec: el Caso de los Muxe, Ms. ENAH, México.

Newbold Chiña, Beverly, 1992, The Isthmus Zapotecs. A matrifocal culture of Mexico, Fort Worth: Harcourt Brace Jovanovich College Publishers.

Pérez Monfort, Ricardo, 2000, "Notas sobre el Estereotipo de la Tehuana", Acervos. Boletín de los Archivos y Bibliotecas de Oaxaca, Vol. 4, México.

Pérez Rojas, Carlos Efraín, 2005, "Video Comunitario y Autorrepresentación”, entrevistado por Gabriela Zamorano, Asistente de Programas Latinoamericanos del Centro de Cine y Video del Museo Nacional del Indígena Americano. En sitio web: Redes Indígenas, www.redesindigenas.si.edu.

Poole, Deborah, 2001, Cultural Diversity and Racial Unity in Oaxaca: Rethinking Hybridity and the State in PostRevolutionary Mexico, Ms., Department of Anthropology, Johns Hopkins University, Estados Unidos.

—, 2004, “An Image of 'our Indian': Type Photographs and Racial Sentiments in Oaxaca", 1920-1940, Hispanic American Historical Review 844(1), pp. 37-82.

Rubin, Jeffrey, 1997, Decentering the Regime: ethnicity, radicalism, and democracy in Juchitán, Mexico, Duke University Press, Durham, N.C.

Starr, Frederick, 1899, Indians of Southern Mexico: an ethnographic album, Chicago. 
—, 1908, In Indian Mexico: a narrative of travel and labor, Forbes, Chicago.

-, 1978 [1902], The Physical Characters of the Indians of Southern Mexico, AMs Press, Nueva York.

Trillo Tenorio, Mauricio, 1999, "Stereophonic Scientific Modernisms: Social Science between Mexico and the United States, 1880s-1930s", The Journal of American History 86 (3), pp. 1156-87.

Turner, Terence, 2002, "Representation, Politics and Cultural Imagination in Indigenous Video", en F. Ginsburg, L. Abu-
Lughod y B. Larkin (eds.) Media Worlds: Anthropology on New Terrain, University of California Press, Berkeley, pp. 75-89.

Wortham, Erica Cusi, 2004, "Between the State and Indigenous Autonomy: Unpacking Video Indígena in Mexico", American Anthropologist, Vol. 106, Núm. 2, pp. 363-368.

Zarauz López, Héctor L., 2004, "La Tehuana en el cine nacional, imágenes de voluptuosidad y recato", Acervos. Boletín de los Archivos y Bibliotecas de Oaxaca, Vol. 7, Núm. 28, pp. 25-36. 